\title{
Fractional Excretion from T1 to T2
}

National Cancer Institute

\section{Source}

National Cancer Institute. Fractional Excretion from T1 to T2. NCI Thesaurus. Code C156576.

The fraction of the administered dose that is recovered from the specimen type, over the interval between $\mathrm{T} 1$ and $\mathrm{T} 2$. 